\title{
Effects of the Continuation Tasks as a Predictor of Pragmatic Competence on Writing Proficiency
}

\author{
Jiajia Xia \\ Guangdong University of Foreign Studies, South China Business College \\ Guangzhou, China
}

172330706@qq.com

Keywords: pragmatic competence, pragmatic writing, the continuation tasks, task-based approach

\begin{abstract}
The paper reports on an experimental research study aiming at investigating the effectiveness of employing the continuation tasks in developing EFL student' pragmatic writing skills. To assess the actual effect of the continuation tasks as a predictor of target language pragmatic competence on writing proficiency, the author proposes a task-based approach to achieve pragmatic appropriateness in writing. It is conducted over two pairs of undergraduate students, of whom one pair is regarded as the control group exposed to the traditional writing, the other as the experimental group exposed to the continuation tasks. Procedures are guided by a task-based framework involving stages: 1) pre-task, 2) task cycle, 3) language focus. Measurement tools include: 1) questionnaires of Pragmatic Writing Skills in the pre \& follow-up test; 2) the assessment \& scores of pre, post \& follow-up writings; 3) interviews. Results indicate the continuation tasks' contributing to more appropriate use of target language pragmatic features in writing. Thus the pedagogical implications of this study suggest providing opportunities for language learners to have interaction with target language writers in foreign language contexts through the continuation tasks.
\end{abstract}

\section{Introduction}

Pragmatic teaching, one of the most important factors affecting the development of pragmatic competence of L2 learners, is the mainstream concern in two languages / foreign language teaching [2][10][15]. Although the fields of pragmatics and writing have been developed considerably during the last 30 years [11][12][17], pragmatics is still underrepresented in researches about writing in China. The traditional pragmatic writing teaching, which, to a great extent, neglects learners' subjectivity in pragmatic acquisition, has contributed to the default of dynamic characteristics of pragmatic writing competence. And some present writing classrooms just unilaterally emphasize the practice of sentences and rhetoric, ignoring the improvement of students' organizational ability. All this has seriously resulted in the lack of chapter consistency and writing logic. Just as professor Liu [14] once mentioned, the development of students' pragmatic competence is largely influenced by their English teachers' teaching content and teaching methods. Relevant researches have been done in view of this. For instance, some researchers [1][3][4][21] explored the role of target language pragmatic knowledge in writing various kinds of letters. And Canale [7] examined the characteristics of the context of language use that determines the appropriateness of utterances. However, few studies tackled the pragmatic uses of EFL [18][22]. In order to help play learners' main role in the process of pragmatic acquisition, the author puts forward the emphasis on the learner-centered learning philosophy in writing pragmatic teaching.

It is universally acknowledged that both of the oral and written discourse are dynamic discourse 
activities conveying information and communication. The term in the discourse can limit the scope of the subsequent statements, "determining the suitability of a sentence or phrase in a particular discourse" [19]. Besides, the textual function of pragmatic presupposition reminds us that pragmatic presupposition serves for the smooth flow of textual information, indicating concentration on the appropriateness of each item in discourse construction both in writing practice and other foreign language skills training. It thus infers that instead of just staying in the wording, phrases or single sentences practice, we would rather combine the individual training and textual perspective, and stimulate students to arrange discourses consciously by means of pragmatic presupposition in writing practice. Hopefully, students in this layer can learn to look at the overall macro-context of chapters before writing, consider the common knowledge between the subject (the author and the reader), the assumptions and the predictor of the reader's knowledge, then arrange the information for the best "accessibility" in writing. Without doubt, All this coincide with the continuation tasks.

\section{The Continuation Tasks and Pragmatics Competence for Writing}

\subsection{What is the Continuation Tasks}

Wang Chuming [20] mentioned: The task design of the continuation task is simple. We can just erase the end of an article, and guide students to read the part of the cut to fulfill the content creatively based on their own understanding. It is considered as a method of combining language output with input to accelerate the improvement of students' language use ability. Since developing pragmatic competence in English is a current need for real-life practice, the continuation tasks can be taken as a right method of this kind. Because its main purpose is to ensure readers to be familiar with the rhetorical routine of anatomical classification and consequently to be able to anticipate certain information with certain language expressions from the reading materials. Aiming at promoting an interactive environment where pragmatic language goals can be accomplished, and facilitating communication and meta-communication for writers and readers to interact in contexts, the continuation tasks can not only serve to highlight the importance of students' working relationship for their ideas' development, but also show its impact on students' pragmatic communication and their creativity of ideas for further writing.

\subsection{How to Tackle Pragmatic Failure in EFL Writing}

Pragmatic competence refers to "the ability to be appropriate and effective to achieve the purpose of communication” [9]. Whereas pragmatic failure is always caused by sociocultural differences as well as lack of linguistic proficiency. This hence indicates that we might misunderstand the observed similarity in reading and writing if we do not take into account the dimension of cross-cultural variation when writing, for "cultures may vary in the social meaning attached to similar linguistic choices” [6]. Although certain studies have confirmed that a good command of the reading-writing tasks can lead to a high level of writing proficiency, there is a dearth of research over the effect of perceived target language pragmatic knowledge through writing. So the continuation tasks can be hailed as an approach for complement where language learners in the second language context can be exposed to the pragmatic features of the target language community and can have contact with the authors to some extent. It means that readers in this way can acquire enough opportunities to apply those pragmatic features appearing in the reading materials to their writing, which hints EFL learners can be immersed in a natural, input-rich and meaningful learning environment, avoiding pragmatic failures to use the target language spontaneously and functionally. Therefore, the continuation tasks in this study was intended to 
developing students' pragmatic competence in English proficiency in the hope of facilitating them with sufficient English knowledge for further interactions and correspondence in writing.

To frame my research, I formulated the questions:

Does the continuation tasks have a significant effect on developing pragmatic competence in the target language writing proficiency?

Accordingly, the null hypothesis is:

The continuation tasks has no significant effect on developing pragmatic competence in the target language writing proficiency.

\section{Methodology}

\subsection{Context of research}

The research was carried out one term involved three segments based on the task-based learning. Materials were from the "new version of the College English Comprehensive Course", the second edition, 1-4 volumes. Due to the fashionable writings in the current English tests in China, the author selected argumentative articles.

\subsection{Participants}

Participants in the study consisted of two pairs of undergraduate students who were viewed as researchers themselves during practice. One pair was regarded as the control group exposed to the traditional writing, the other as an experimental group exposed to the continuation tasks.

\subsection{Approach}

Based on the task-based approach with qualitative and quantitative analysis to examine specific examples in particular contexts, the research compared the students' performance respectively on the pre \& post, and even the follow-up test.

\subsection{Procedure}

The first writing task used as pre-test was administrated at the beginning of the term, the second as post-test in the middle-term, while the third as follow-up at the end of the term. Procedures for writing practice were mainly guided by a task-based learning framework involved stages: 1) pre-task, 2) task cycle, 3) language focus. Measurements included: 1) pre, post \& follow-up test for Pragmatic Writing Skills ; 2) the assessment \& scores analysis of tests.

1). Pre-task:

Step 1: For the appropriate selection of reading and writing materials, the author interviewed four subjects identify their pragmatic writing problems and needs.

Step 2: To ensure the improvement of the subjects' pragmatic writing awareness, the author conducted a list of pragmatic writing skills them to study theoretically for successively 3 weeks.

Step 3: The subjects were taught how to read for the writer's intention, and to identify the main and supporting ideas, which is considered as the discourse processing. Besides, they were conducted on how to display their grasp of the pragmatics of information transaction in the materials.

2). Task cycle:

The writing tasks lasted for 30 minutes. And students were encouraged to develop expectations of the reading text and hazarding "guesses" about the coming content. While exact reference about the selected topic was welcomed in the practice. Discussion were encouraged between the pairs for better understanding of the material and the topics. Then with the fulfillment of the task, the slips of 
the writing task were collected and prepared for subsequent analysis.

3). Language focus:

On the stage of independent creative discourse, students attempted to create beautiful articles based on the theme, the class structure and the written discourse.

\subsection{Methods of data collection}

The data collected included observation, interviews, and students' written outcomes. To assess the four students' performance, their writing discourse were examined at three levels--clause, sentence and paragraph, and were rated by two native English speakers who are experts in teaching academic writing.

\subsection{Assessment}

Questionnaires about English use in different tasks were made for better testing students' pragmatic writing skills respectively. Results showed that there were no significant differences at the beginning, while there were visible differences after the task cycle. And all the writing were scored by two American foreign teacher who teaches writing. While the final score for each writing is the average.

\section{Finding and Discussion}

1 The experimental group performed more qualitatively than the control one's.

2 As a means of language communication, writing is not just the construction of words, paragraphs, and texts; it is a channel of communication restricted by various cultural factors. This study shows that it is very vital for learners to be equipped with the appropriate way of putting their ideas in the writing which at one point boosts an intercultural communication with the target language authors and at another point develops their target language pragmatic competence. Students' reflections were as follows:

Pre-interviews:

1) We have the practice of writing every week, but I am still not sure about my writing.

2) Sometimes, I am confused of the words selection for my writing, let alone the accuracy for writing.

3) Writing is a headache for me.

Post-interviews:

1) The continuation tasks helps me to conduct the obtained knowledge not only in my writing but in my daily usage and I have found that what I have acquired can maintain for a considerably long period of time.

2) Through the continuation tasks, I come closer to the author and the target language culture.

3) I gradually get the awareness of target language pragmatic features in effective cross-cultural communication in the reading materials for my writing.

4) Through this approach, I become sensitive not only to the discrete points in the language expression in the reading materials but to the language diversity of social interaction reflected in it.

5) when I was analyzing the text plot, I gradually understood the contextual context regardless of the ambiguity, which helped determine the precise meaning of words in the text.

6) I come to realize how to identify differences in expression habits and ways.

7) In a pragmatic sense, it helps me to use the resources to design utterances for my continuation writing.

All this more or less points out learners who fail in performing a native-like language production 
can be considered to be a result of low linguistic proficiency, which puts a side effect on learners' language competence, as well as on their oral and written communication with native readers/hearers. In contrast, the continuation tasks provides various of discourse options for readers and creates opportunities for the performance and practice of target language pragmatic competence in reality.

3 As to the assessment of students' writing, Sasaki's [16] rating scales (RS) were adopted. Appropriateness and grammar/structure were measured for all the writing with level criteria in 4 grades ( points: $1 \sim 2,3 \sim 5,6 \sim 8,9 \sim 10$ ). Score are as follows respectively:

Table 1\&2:

\begin{tabular}{|l|l|l|l|}
\hline The experimental group & pre-task & post- task & follow-up \\
\hline Student A & 6 & 7.5 & 7.5 \\
\hline Student B & 6.5 & 7 & 8 \\
\hline
\end{tabular}

\begin{tabular}{|l|l|l|l|}
\hline The control group & pre-task & post- task & follow-up \\
\hline Student A & 5.5 & 6 & 6.5 \\
\hline Student B & 6 & 6.5 & 6.5 \\
\hline
\end{tabular}

These tables indicate that both pairs of language learners (the control group and the experimental group) had a better performance on the writing tasks than before. But it also reflected that learners who were linked to the native English authors through reading outperformed the other pair who merely received writing instruction and did not have the opportunity to interact with the target language authors. In other words, it means that the continuation tasks is not just a matter of knowing the semantic meanings of the words, but it helps enhance writers' alignment more closely to text function and process control. Therefore, with respect to the findings obtained in the current study, the null hypothesis of the study which states that the continuation tasks has no significant effect on developing pragmatic competence in the target language writing proficiency is rejected.

\section{Conclusions and implications for further research}

As what Hartnett mentioned [8], a focus on learners' pragmatic competence through a pragmatic-functional approach to writing ensures a meaningful communicative use of English. Results of this study indicate that the continuation tasks, which has been testified to be a form of socially-embedded and socially-oriented text reproduction, conducts valuably to acquire pragmatic features, as it succeeds in exerting an enormous influence on both textual and discourse layers for pragmatic improvement in the target language writing proficiency. It therefore promotes some pedagogical implications for the writing tests in exams like CET 4\&6, TEM 4\&8, and even IELTS and TOEFL. Yet the faculty should make efforts to bridge the gap between pragmatic studies and their pedagogical implications for the writing teaching. A great deal of work needs to be done to take this forward.

\section{Acknowledgments}

The author wishes to acknowledge the support from the Key Program of the English language and Literature of Guangdong Province, 2016, Guangdong Educational Research Planning Project “A Study of the Wash-back Effect of CET4 Reform on College English Teaching” (Project Code: 
2013JK348) and the project “A Study on Cultivating Learners' Pragmatic Competence with The Continuation Tasks”( Project Code: 15-005B) in Guangdong University of Foreign Studies, South China Business College in the writing up of this paper.

\section{References}

[1] Al-Ali, M. N. Genre-Pragmatic Strategies in English Letter-of-Application Writing of Jordanian Arabic-English Bilinguals [J]. International Journal of Bilingual Education and Bilingualism, 2006, 9(1), 119-139. http://dx.doi.org/10.1080/13670050608668633

[2] Alcón-Soler, E.\& A. Martínez-Flor (eds.). Investigating Pragmatics in Foreign Language Learning, Teaching and Testing [D]. Bristol: Multilingual Matters, 2008.

[3] Al-Khatib, M. A. The Pragmatics of Letter-Writing [J]. World Englishes, 2001, 20(2), 179-200. http://dx.doi.org/10.1111/1467-971X.00208

[4] Bagwasi, M. M. Pragmatics of Letter Writing in Setswana [J]. Journal of Pragmatics, 2008, 40(3), 525-536. http://dx.doi.org/10.1016/j.pragma.2007.11.009

[5] Bills, E. Politeness in teacher-student dialogue in mathematics: A social-linguistic analysis, For the Learning of Mathematics [J/OL], 2000, $20 \quad$ (2), 40-47. http://www.jstor.org/discover/10.2307/40248326?

[6] Blum Kulka, S. \& J. House. Cross-cultural and situational variation in requestive behavior. In S. Blum Kulka, J. House, \& G. Kasper (eds.), Cross-cultural Pragmatics: Requests and Apologies. Norwood [D], NJ: Ablex, 1989, 123-154.

[7] Canale, M. The Measurement of Communicative Competence [J]. Annual Review of Applied Linguistics,1988, 8, 67-84.

[8] Hartnett, C, G. A Functional Approach to Composition Offers an Alternative[J]. Composition Chronicle: Newsletter of Writing Teachers, 1997, 10 (5), 5-8.

[9] Jiang, Z. H. The Study of Pragmatic Competence in Transitional Pragmatics [M]. Beijing: Peking University Press, 2013.

[10]Kasper, G. \& K. R ose. Pragmatic Development in a Second Language [M]. Oxford: Blackwell, 2002.

[11]Leech, G. The principles of pragmatics [M]. London and New York: Longman, 1983.

[12]Levinson, S. Pragmatics [M]. Cambridge and New York: Cambridge University Press, 1983.

[13] Li, Y. H. New College English Integrated Course 2 [M]. Shanghai Foreign Language Education Press, 2015.

[14]Liu, J. D. \& Huang, W. Y. Chinese EFL Learners' English Proficiency and Their Pragmatic Competence Development [J]. Foreign Language in China, 2012, 9 (1), 64-70.

[15]Rose, K. \& G. Kasper. Pragmatics in Language Teaching [C]. Cambridge: Cambridge University Press, 2001.

[16][16] Sasaki, M. Investigating EFL students' production of speech acts; A comparison of Production Questionaires and role plays [J]. Journal of Pramatics, 1998, 30(4), 457—484.

[17] Sacks, H. Lectures on conversation [C]. Vol. 1. Oxford: Blackwell, 1992.

[18] Salem, A. A. The Effect of Writer's Workshop Approach to Develop Functional Writing Skills of Primary Stage Pre-Service English Language Teachers in Egypt [J]. International Journal of Applied Linguistics \& English Literature (IJALEL), 2013, 5 (2), 70-80.

[19] Vennem ann T. Topic, Sentence Accent and Ellips is: A Proposal for Their Form a 1 Treatment. In Keenan, EL. Form a l Semantics of Natural Language [M]. Cambridge: Cambridge University Press, 1975. 
[20]Wang, C. M. A Study of the Continuation Task as a Proficiency Test Component [J]. Foreign Language Teaching and Research, 2013, 45 (5), 707-718.

[21] Youn, S. J. Measuring Syntactic Complexity in L2 Pragmatic Production: Investigating Relationships among Pragmatics, Grammar, and Proficiency [J]. System, 2014, 42, 270-287. http://dx.doi.org/10.1016/j.system.2013.12.008

[22]Zhuge, X. \& Wu, G. An exploration into Pragmatic Failure in EFL learning [J]. Sino-US English Teaching, 2005, 2 (7), 73-78. 